\title{
The Bright and Dark Side of Pre-existing Social Ties and Relational Orientation in Research Collaborations in South Korea*
}

\author{
Martin HEMMMERT ${ }^{1}$, Jae-Jin KIM ${ }^{2}$
}

Received: August 27, 2019 Revised: October 19, 2019 Accepted: November 15, 2019

\begin{abstract}
Informal networks between individuals are widely seen as important in East Asian business systems. However, while the performance implications of guanxi in China have been extensively studied, much less is known on how informal networks may influence business outcomes in other East Asian countries. We examine informal networks in inter-organizational research collaborations in South Korea by studying the role of pre-existing social ties and relational orientation in new product development (NPD) collaborations and university-industry research (UIR) collaborations. We conduct an interview-based, in-depth case analysis of five NPD collaborations and five UIR collaborations. Pre-existing social ties and relational orientation are prevalent in both types of research collaborations. However, they have different consequences for collaboration outcomes. Pre-existing social ties strongly vary in their types and strength, and negatively affect collaboration outcomes unless they result in the selection of competent and motivated partners. Relational orientation manifests itself in a task-related and social exchange between collaboration partners, which contributes to outcomes such as knowledge acquisition and business performance. Korean collaboration managers should rely only on pre-existing social ties that are well-aligned with task-related requirements when initiating and conducting research collaborations. However, the creation of strong relationships between collaboration team members of partnering organizations should be encouraged.
\end{abstract}

Keywords : Research Collaboration, Pre-existing Social Ties, Relational Orientation, Knowledge Acquisition, Business

Performance, South Korea

JEL Classification Code : L14, M10, M21, O32

\section{Introduction}

Informal networks between individuals are believed to be highly important in the business systems of East Asian countries (Yang \& Horak, 2019). Within East Asia, the

\footnotetext{
* This work was supported by Global Research Network program through the Ministry of Education of the Republic of Korea and the National Research Foundation of Korea (NRF-

2017S1A2A2041806) and a Korea University Business School Research Grant.

1 First Author, Professor, School of Business, Korea University, Korea. [Postal Address: 145, Anam-Ro, Seongbuk-Gu, Seoul, 02841, Republic of Korea]. Email: mhemmert@korea.ac.kr

2 Corresponding Author, Assistant Professor, School of Business Administration, Hoseo University, Korea. [Postal Address: 12, Hoseodae-gil, Dongnam-gu, Cheonan-si, Chungcheongnam-do, Republic of Korea]. Email: jkim@hoseo.edu

(c) Copyright: Korean Distribution Science Association (KODISA)

This is an Open Access article distributed under the terms of the Creative Commons Attribution Non-Commercial License (http://Creativecommons.org/licenses/by-nc/4.0/) which permits unrestricted noncommercial use, distribution, and reproduction in any medium, provided the original work is properly cited.
}

relevance of guanxi in China was intensively studied in business and management research (e.g., Luo, Huang, \& Wang, 2012; Bu \& Roy, 2015; Burt \& Burzynska, 2017). Similar to China, informal networks are seen as prevalent in the economy and society of South Korea (hereafter, Korea) (Yee, 2000; Lew, 2013), regardless of the country's rapid development and transition towards becoming a newly industrialized economy (NIE). While informal networks previously received limited research attention in the Korean context, an increasing number of studies has been conducted in recent years (Lew, 2013; Horak, 2014; Yee, 2015; Horak \& Taube, 2016; Horak, 2017; Yang \& Horak, 2019). These recent studies have advanced our understanding of the nature and variety of informal networks in Korea. However, much less is known about the networks' influence on business outcomes.

For gaining an understanding on the processes through which informal networks may influence business outcomes, it is useful to consider them across different stages (Chen \& Chen, 2004), including the relationship history between 
partners and their interaction during a business exchange. One important aspect of informal networks are pre-existing social ties, understood as social ties between individuals that were established prior to focal business exchanges (Bstieler \& Hemmert, 2010). While studies on inter-organizational research collaborations (hereafter, research collaborations) found that pre-existing social ties are unrelated to relationship quality and collaboration outcomes (Bstieler \& Hemmert, 2010; Hemmert, 2019), these quantitative studies did not provide insights on the processes that result in the observed outcomes, and the potential positive effects (the bright side) or negative effects (the dark side) of pre-existing social ties for outcomes.

Another important phenomenon related to informal networks is relational orientation, understood as the degree to which individuals engage in establishing and maintaining inter-personal relationships during a given business exchange. Korean companies and managers are seen as being strongly relationship-oriented in business exchanges (Yang, 2006). Empirical studies examined relational governance in inter-organizational business exchanges in Korea and found that it plays an important role for exchange outcomes (Goo, Kishore, Rao, \& Nam; 2009; Bstieler \& Hemmert, 2015). Yet, similar to pre-existing social ties, little is known about the specific mechanisms through which relational orientation in Korean business articulates itself, and how it may contribute positively or negatively to outcomes of business exchanges and collaborations.

This exploratory study intends to advance the understanding of the role of informal networks in business exchanges in Korea through an in-depth analysis of ten research collaborations. Such research collaborations are highly important for Korean firms, which strongly rely on technological innovation for competing globally (Hemmert, 2018). We aim to open the black box of the performance implications of informal networks in a Korean business context by (1) examining the prevalence and nature of preexisting social ties and relational orientation in research collaborations, (2) identifying the processes and mechanisms through which pre-existing social ties and relational orientation articulate themselves in these collaborations, and (3) studying the bright and dark sides of pre-existing social ties and relational orientation for collaboration outcomes.

\section{Literature Review}

\subsection{Informal Social Ties}

Informal social ties are strongly prevalent in Korea (Lew, 2013; Horak, 2014), where a rich terminological variety related to types and categories of social ties exists, including the concepts of yongo (personal relationships; mostly associated with family, school and regional ties), inmaek (human networks), pabol (cliques) and yonjul (gains from connections) (Yang \& Horak, 2019). Pabol and yonjul have clearly negative connotations, as they are associated with factionalism and illegal transactions, respectively. In contrast, yongo and inmaek are regarded as more neutral terms to describe informal social ties and networks.

Informal social ties in Korea are described as a type of social capital (Lew, Chang, \& Kim, 2013) with hierarchical, collectivistic and private attributes that are based on Confucian traditions (Yee, 2015). Membership in some types of networks, such as families, is strictly ascribed. Other types of networks, such as friendship circles and hobby clubs, can be joined and exited more flexibly. Hence, individuals have an a priori choice with whom they will create informal social ties in the future. Once they become members of specific networks, however, they feel an obligation to help each other and provide other network members with support when needed (Horak \& Taube, 2016).

There is an agreement that informal social ties play an important role not only in the personal and professional lives of Koreans, but also for various characteristics of Korean business (Yee, 2000; Lew, Chang, \& Kim, 2013; Horak, 2014; Yee, 2015; Horak, 2017). Managers perceive that preexisting social ties are frequently leveraged in specific business contexts, such as negotiations with business partners or staff recruitment and promotion decisions (Horak, 2014; 2017). These perceptions implicitly suggest that social ties have a bright side through their effectiveness for the career advancement of professionals and for enhancing business performance (e.g., when companies seek to acquire business partners such as customers or suppliers). However, they may also exhibit a dark side through lock-in effects: emotional or moral obligations to continuously engage with specific partners who are not necessarily the most suitable ones to achieve business-related goals (Ledeneva, 2018).

However, there is limited research on the actual influence of pre-existing social ties on business performance. Two studies on the role of pre-existing social ties in research collaborations found that pre-existing social ties are unrelated to various performance aspects (Bstieler \& Hemmert, 2010; Hemmert, 2019). These findings are in clear contrast to widespread perceptions about the importance and effectiveness of pre-existing social ties in Korean business exchanges, and indicate a need to study the processes that render pre-existing social ties effective or ineffective in specific business contexts such as research collaborations.

\subsection{Relational Orientation in Business Exchanges}

Aside from the role of pre-existing social ties, exchanges in Korean business are also perceived as strongly relationshiporiented (Yang, 2006). Similar to informal social ties, this relational orientation can be linked to Confucian traditions, which emphasize the importance of nurturing and maintaining strong relationships with specific individuals, such as family 
members or friends (Lee, Choi \& Wang, 2013; Hemmert, 2018). In contrast to Western thinking, which places high importance on adherence to general rules, Korean thought traditions underscore the precedence of personal relationships over abstract principles (Yum, 1988).

As a result of its rapid growth and development, Korea has entered the group of rich industrialized countries. Moreover, various institutional reforms have been implemented in Korea since the Asian financial crisis to strengthen transparency and the rule of law (Kwon, 2010). Due to these economic advances and institutional transitions, the reliance on relational governance in business exchanges may be expected to weaken and gradually yield to a rulebased, impersonal exchange regime (Peng, 2003).

However, it is unclear whether relational governance is being replaced by contractual, rule-based governance in business exchanges in Korea. Goo et al. (2009) observed that in inter-firm IT outsourcing agreements, contractual agreements support various aspects of relational governance. Bstieler and Hemmert (2015) found that relational governance is more relevant than contractual governance for outcomes of NPD collaborations, and that there is a substitution effect between contractual and relational governance. These findings suggest that relational governance still plays an important role in business exchanges in Korea. However, little is known on the specific processes through which such strong relational orientation materializes in ongoing exchanges, and how these processes affect outcomes.

\subsection{Research Collaborations}

Research collaborations are a relatively recent phenomenon in Korea. For most of the twentieth century, Korean companies have focused on the imitation and importation of technologies from advanced countries as effective methods of technological catch-up (Lee \& Lim, 2001). In recent decades, however, many Korean firms have reached the technological forefront, and have rapidly scaled up their research and development (R\&D) activities (Park \& Shim, 2019). As a result, Korea now has one of the highest $R \& D$ intensities in the world (OECD, 2017). Various megatrends, including stronger global competition, accelerating technological progress and lower entrance barriers in many technology-intensive industries have also induced companies to seek more research collaborations (West \& Bogers, 2014). Research collaborations with other firms and with universities are a particularly effective means for companies to strengthen their technological competitiveness (van de Vrande, de Jong, Vanhaverbeke, \& de Rochemont, 2009).

Therefore, Korean firms are now engaging much more frequently in such research collaborations (Lee, Park, Yoon, \& Park, 2010). However, many Korean companies find the effective management of research collaborations highly challenging. In Korea's collectivistic society, there is a strong distinction between in-groups and out-groups (Yum,
1988). Therefore, it is difficult to develop trust into external organizations and their representatives (Huff \& Kelley, 2003). Studies of research collaborations in Korea show that participating companies struggle to establish trust with their partners (Hemmert, Bstieler, \& Okamuro, 2014) and to leverage collaboration outcomes effectively for innovation (Eom \& Lee, 2010). In other words, while research collaborations are now a highly relevant mode of technology development for Korean firms, the management of such collaborations is perceived as difficult. In view of the hurdles that Korean companies and organizations are facing in the management of such collaborations, informal networks could potentially play an instrumental role in introducing potential partners to each other or in enhancing the effectiveness and outcomes of collaboration projects. However, the actual role of informal networks in research collaborations in Korea remains unexplored.

\subsection{Research Questions}

In order to advance our understanding of the role of informal networks for outcomes of research collaborations in Korea, this study focuses on the following research questions:

(1) How prevalent are and what is the nature of preexisting social ties in research collaborations in Korea?

(2) What influences do pre-existing social ties have on the initiation and outcomes of research collaborations in Korea, and what are the processes that underlie their bright or dark side?

(3) How strong is relational orientation in research collaborations in Korea, and through which mechanisms does it manifest itself?

(4) What is the role of relational orientation for outcomes of research collaborations in Korea, and what are the underlying processes of its bright or dark side?

\section{Research Methodology}

\subsection{Data Collection}

In this study, two types of research collaborations are examined: (1) NPD collaborations between companies, defined as project-based inter-organizational exchange relations between two independent firms involved in the conception, testing, production, or marketing of a new product; and (2) UIR collaborations, defined as projectbased collaborative research relationships between universities and companies aiming at the generation or transfer of new products, technologies, or processes. Specifically, five NPD collaborations and five UIR collaborations were studied in-depth through on-site hearings of collaboration partners.

The NPD collaboration cases were selected among 47 
collaboration projects in the Korean machinery industry on which questionnaire responses were initially collected, seeking to capture different patterns of pre-existing social ties and relational orientation. As the collaborating companies were reluctant to disclose the identities of their partners, the hearings were limited to one side of each NPD collaboration.

The on-site interviews were conducted in a semistructured manner. We asked collaboration partners about the pre-existing ties among them, the initiation of the collaboration, how the collaboration progressed, how the partners interacted and resolved conflicts, and collaboration outcomes. The interviews lasted 40 to 90 minutes. The interview contents were recorded in detailed protocols, which were subsequently analyzed to detect common or divergent patterns of interaction and outcomes across the research collaborations.

\subsection{Sample Information}

Sample information on the research collaborations included in this study is provided in Tables 1 and 2. The NPD collaboration projects lasted 12 to 21 months and focused on the development of new industrial machinery and industrial materials.

The UIR projects had a duration of two years and focused on the development of new technologies in technology-intensive industries, including biotechnology and medicine, robotics and security software.

All ten research collaborations were between Korean partners, except for one NPD collaboration where one partner was from Japan and one UIR collaboration where one out of two university partners was from the US.

Table 1: Sample Information of NPD Collaborations

\begin{tabular}{|l|c|}
\hline \multicolumn{1}{|c|}{ Attribute } & Frequency \\
\hline Project length & 3 \\
$12-15$ months & 2 \\
$18-21$ months & \\
\hline Industry classification & 4 \\
Industrial machinery & 1 \\
Industrial materials & 2 \\
\hline Size of companies & 3 \\
50 - 300 employees & \\
$>300$ employees & \\
\hline
\end{tabular}

Table 2: Sample Information of UIR Collaborations

\begin{tabular}{|l|c|}
\hline \multicolumn{1}{|c|}{ Attribute } & Frequency \\
\hline Project length & 5 \\
\hline 24 months & 2 \\
\hline Industry classification & 2 \\
$\quad$ Biotechnology and medicine & 1 \\
Robotics & 2 \\
Security software & 3 \\
\hline Size of companies & \\
$\quad<100$ employees & 3 \\
$100-200$ employees & 2 \\
\hline Size of university labs (full-time equivalents) & \\
<10 employees & \\
10-30 employees & \\
\hline
\end{tabular}

\section{Analysis of Research Collaborations}

To examine the role of pre-existing social ties and relational orientation in each stage of the research collaborations, the NPD collaborations and UIR collaborations are analyzed with a focus on the following topics: relationship history and initiation of each collaboration; interaction channels and intensity; collaboration challenges and remedies; and collaboration outcomes. The findings are summarized in Tables 3 and 4 .

\subsection{NPD Collaborations}

Relationship history and initiation of collaboration. In two cases, the NPD collaborations were initiated based on long-term business relationships with customer companies that lasted for approximately 20 years. Supplier-customer business relationships for industrial equipment were extended into NPD collaborations.

"OEMs (original equipment manufacturers) ask us to develop pumps for their models. We cannot do business with OEMs without that kind of development and testing collaboration." (Company A)

"We develop high-end office equipment for OEMs and produce and sell it later to these companies."(Company B)

Some individual managers from the partner companies personally knew each other before the NPD collaborations. However, from the perspective of the interviewees, this relationship history has not been important for the ongoing research collaborations.

"The relationship experience in itself is not relevant. When we become acquainted with each other, we deliberately avoid exploring common backgrounds, such as school or region. Everything is focused on the actual work, capabilities, and performance." (Company A)

"The whole relationship is very much task-driven. We do not feel any particular importance of the relationship experience for the current business. " (Company B)

In the remaining three cases, there were no pre-existing business relationships between the NPD collaboration partners. In one case, the partners met each other at a trade exhibition. In the second case, they were introduced to each other through a governmental organization that acted as a mediator for technology collaborations. In the third case, a manager of the interviewed company had previous working experience with the partner company. Therefore, there were close pre-existing social ties between NPD collaboration team members from the two companies in this case, which also included common memberships in alumni networks. In all three cases, these mechanisms served as a basis to create 
trust and initiate NPD collaborations between the companies.

"We met our partner at an expo. We knew most of the leading companies in the factory automation industry were German and Japanese. However, we found that the way the Japanese design the products is more compatible with our standards and easier to understand. What first convinced us to trust this partner was the belief that they have significant engineering capabilities to produce the model they design." (Company $C$ )

Table 3: Summary of NPD Collaboration Analysis

\begin{tabular}{|c|c|c|c|c|}
\hline Collaboration case & $\begin{array}{l}\text { Relationship history and } \\
\text { initiation of collaboration }\end{array}$ & $\begin{array}{l}\text { Interaction channels } \\
\text { and intensity }\end{array}$ & $\begin{array}{c}\text { Collaboration challenges } \\
\text { and remedies }\end{array}$ & Outcome evaluation \\
\hline$A$ & $\begin{array}{l}\text { Long-term business } \\
\text { relationship; personal } \\
\text { acquaintances }\end{array}$ & $\begin{array}{l}\text { Frequent face-to-face } \\
\text { meetings; regular social } \\
\text { after-work gatherings }\end{array}$ & $\begin{array}{l}\text { Occasional disagreements } \\
\text { on quality issues; overcome } \\
\text { by mutual persuasion and } \\
\text { compromising }\end{array}$ & $\begin{array}{l}\text { Positive } \\
\text { NPD knowledge acquisition }\end{array}$ \\
\hline $\mathrm{B}$ & $\begin{array}{l}\text { Long-term business } \\
\text { relationship; personal } \\
\text { acquaintances }\end{array}$ & $\begin{array}{l}\text { Initial capability-based trust } \\
\text { extended into personal trust } \\
\text { through regular social } \\
\text { gatherings }\end{array}$ & $\begin{array}{l}\text { Disagreements on price and } \\
\text { product specifications; } \\
\text { overcome by continued } \\
\text { investment into relationship }\end{array}$ & $\begin{array}{l}\text { Positive } \\
\text { technological knowledge } \\
\text { acquisition; strengthened } \\
\text { NPD capabilities }\end{array}$ \\
\hline $\mathrm{C}$ & $\begin{array}{l}\text { No pre-existing relationship; } \\
\text { met at trade exposition; good } \\
\text { reputation of partner } \\
\text { company }\end{array}$ & $\begin{array}{l}\text { Daily phone communication; } \\
\text { frequent face-to-face } \\
\text { meetings in early } \\
\text { collaboration stage with } \\
\text { subsequent social } \\
\text { gatherings }\end{array}$ & $\begin{array}{l}\text { Price and quality } \\
\text { disagreements; overcome by } \\
\text { compromising and showing } \\
\text { commitment to collaboration }\end{array}$ & $\begin{array}{l}\text { Positive } \\
\text { technological knowledge } \\
\text { acquisition; new patents; } \\
\text { increased profits }\end{array}$ \\
\hline$E$ & $\begin{array}{l}\text { Personal relationships } \\
\text { (collaboration team member } \\
\text { previously worked for partner } \\
\text { company) }\end{array}$ & $\begin{array}{l}\text { Daily phone or email } \\
\text { communication; face-to-face } \\
\text { meetings once or twice a } \\
\text { month with subsequent } \\
\text { social gatherings }\end{array}$ & $\begin{array}{l}\text { Perceived breach of trust by } \\
\text { partner (development of } \\
\text { copy product); no } \\
\text { compromising; no resolution }\end{array}$ & $\begin{array}{l}\text { Negative } \\
\text { termination of collaboration } \\
\text { without positive outcomes }\end{array}$ \\
\hline
\end{tabular}

Table 4: Summary of UIR Collaboration Analysis

\begin{tabular}{|c|c|c|c|c|}
\hline Collaboration case & $\begin{array}{l}\text { Relationship history and } \\
\text { initiation of collaboration }\end{array}$ & $\begin{array}{l}\text { Interaction channels } \\
\text { and intensity }\end{array}$ & $\begin{array}{c}\text { Collaboration challenges and } \\
\text { remedies }\end{array}$ & Outcome evaluation \\
\hline$A$ & $\begin{array}{l}\text { Professor co-founder of } \\
\text { company; personal } \\
\text { relationship with CEO }\end{array}$ & $\begin{array}{l}\text { Mostly email and phone } \\
\text { communication; occasional } \\
\text { face-to-face meetings and } \\
\text { social gatherings }\end{array}$ & $\begin{array}{l}\text { No particular collaboration } \\
\text { challenges }\end{array}$ & $\begin{array}{l}\text { Positive } \\
\text { Company: NPD } \\
\text { knowledge; } \\
\text { patent; new staff members } \\
\text { University: research } \\
\text { funding; student raining }\end{array}$ \\
\hline $\mathrm{C}$ & $\begin{array}{l}\text { Met at academic } \\
\text { conference; company well- } \\
\text { reputed }\end{array}$ & $\begin{array}{l}\text { Occasional phone and } \\
\text { Email communication; } \\
\text { quarterly face-to-face } \\
\text { meetings, but no social } \\
\text { gatherings }\end{array}$ & $\begin{array}{l}\text { Difficult to secure contract } \\
\text { agreement with US university } \\
\text { partner; transfer office } \\
\text { perceived as unhelpful and } \\
\text { bureaucratic; no effective } \\
\text { remedies }\end{array}$ & $\begin{array}{l}\text { Negative } \\
\text { Company: no successful } \\
\text { market introduction } \\
\text { University: no good fit of } \\
\text { competencies with } \\
\text { company expectations }\end{array}$ \\
\hline$E$ & $\begin{array}{l}\text { Company has been supplier } \\
\text { of research materials for } \\
\text { university; professor knows } \\
\text { sales manager }\end{array}$ & $\begin{array}{l}\text { Regular email and phone } \\
\text { communication; monthly } \\
\text { face-to-face meetings and } \\
\text { social gatherings }\end{array}$ & $\begin{array}{l}\text { No particular collaboration } \\
\text { challenges }\end{array}$ & $\begin{array}{l}\text { Positive } \\
\text { Company: NPD } \\
\text { knowledge, sales } \\
\text { University: new patent }\end{array}$ \\
\hline
\end{tabular}


"The governmental organization had a program in which it introduced companies to each other on projects related to technological collaboration. Its role was mainly limited to mediation. However, we felt we could trust the partner since we believed that the partner will not be able to behave opportunistically within this kind of governmentally monitored program. We also thought that all companies that were accepted for participation in the program, had a certain minimum level of managerial and technological capabilities." (Company D)

"Initially, there was a high amount of trust within the inter-organizational team, mainly because one team member from our company was initially working for the partner company and knew the partner's team members, which were his former colleagues, very well." (Company E)

Interaction channels and intensity. The frequency and intensity of interaction between NPD collaboration partners varied among the studied projects, depending on the geographical distance between the partners and the perceived need for interaction to conduct the collaborative development tasks. However, in all collaborations, the partners invested time and effort to establish and maintain close working relationships. The interaction between them was extended into after-work activities.

"When working with Japanese OEMs, they prefer face-toface interaction and therefore send people once or twice a month for four to five days each. The Japanese expect to be treated by us and to go with us to Karaoke bars, saunas, and so on. We regard this as an extension of our work, and practically there is no clear line between workrelated and private interaction." (Company A)

"We built a joint team with six members: two from our firm, two from the partner firm, and two from an independent research institute. However, all team members worked separately for their companies. We were working intensively together with frequent phone calls and e-mails. Moreover, we had team meetings twice a month. After these meetings, we used to go out together for some after-work activities." (Company E)

Across the NPD collaborations, the companies focused primarily on task-related performance for establishing a trusted working relationship with their NPD partners.

"In a supplier-customer relationship with OEMs, the task is how we can gain their trust. Trust is clearly task-and performance-oriented. In order to develop trustful relations, we have to offer good quality and competitive prices and delivery schedules." (Company A)

Additionally, the relationship was in some cases also enhanced by the personal interaction between team members of the NPD collaboration partners.

"We were basically starting from the outset under the assumption that we trust each other. Personal relationships were not explicitly considered. However, later on, we also noticed that it helps to know each other well when working together. The after-work gatherings definitely helped us to deepen our mutual trust and understanding and to exchange information." (Company B)

"There were very important ties on a personal level, which made it very easy at the beginning to work together." (Company E)

Collaboration challenges and remedies. In the NPD collaborations, disagreements between the partnering companies occurred on task-related matters such as the price of materials or the quality of newly developed products, and were rooted in diverging financial interests of the partners.

"Typical disagreements were on the price or the quality of their supply parts. The quality also has implications for the design, which we did together. For instance, we wanted more compact parts, which allowed a better design." (Company C)

In one NPD collaboration, a conflict occurred due to one company's behavior, which was perceived as opportunistic by the partner company. As a result, an initially task-related disagreement evolved into inter-personal conflicts.

"A crucial situation occurred when it became apparent that the partner was developing a copy product of our jointly developed product by using our jointly acquired knowledge to increase its market share and profits. Formally, this was not a breach of the partnership contract, since there was no clause forbidding such a thing. However, of course, we were unhappy and felt betrayed by the partner. Initially the disagreements were clearly task-related, but later on developed into personal, emotional conflicts." (Company E)

Conflict resolution efforts focused on overcoming taskrelated disagreements by mutual persuasion or by compromise, in the expectation that such compromises are worthwhile.

"We tried to persuade each other. There was quite a strong knowledge overlap between the OEMs and us. We knew each other's business. At the end, we typically settled on some compromise." (Company A)

In the case of the NPD collaboration where the partner's behavior was seen as opportunistic, however, conflict resolution efforts failed because of a lack of willingness to compromise. 
"Still, we tried to save the partnership by setting up a compromise for this issue. However, this compromise was turned down by the executives of both firms. Each side clearly wanted to maximize its own profits. As a result, the partnership broke down, and the marketing for the jointly developed product is now done separately." (Company E)

The strong discerned pre-existing social ties between members of the NPD collaboration team were perceived as a reason for this failure. The strong ties resulted in a failure to clearly spell out mutual expectations and responsibilities at the beginning of the collaboration, and subsequent interaction problems among team members.

"In a way the strong personal ties contributed to the failure of the partnership in the later stage since the partnership contract was not written very carefully and professionally. Moreover, when the relationship turned uneasy, the personal ties between several team members made it even more uncomfortable to deal with each other. It would have been easier to work on a purely professional basis without any burden of personal acquaintance." (Company E)

Collaboration outcomes. Except for one project that ended in failure due to the inability of the partnering companies to resolve a conflict, the interviewed managers evaluated the outcomes of their NPD collaborations positively. Collaboration outcomes included technological knowledge acquisition and financial outcomes, including sales and profits.

"We acquired a lot of technological knowledge, which enabled us to develop products on our own. As a result, we are now the market leader in Korea in our main business lines." (Company B)

"We learned about molding technology to a considerable degree. This partnership had a strong positive impact on our business. It helped us to increase our sales and profits. Our market share is also going up." (Company D)

\subsection{UIR collaborations}

Collaboration initiation. Three collaboration cases between companies and universities were initiated based on previous exchange relationships. In the first case, the university professor was a co-founder and stakeholder of the partner company.

"The university professor is a founding member of our company and holds a small ownership share. He has offered us a lot of advice in the past and is familiar with the president of the company." (UIR-A Company)

In the second case, the professor had previously worked for the partner company as the director of the research center.
Therefore, the professor and the company CEO knew each other personally before the focal UIR project.

"The professor was associated with our company. He and the CEO discussed potential ways of how the company and the university may collaborate." (UIR-B Company)

In the third case, the company was a supplier of scientific equipment and materials for the university. The university professor became acquainted with operations and sales executives of the company due to frequent purchasing interactions. This relationship triggered university and company representatives to initiate research collaboration.

"I became familiar with this company when I purchased their materials for our education programs. I did not have much contact with the CEO of the company, but instead became acquainted with their sales manager and director through the purchasing transactions." (UIR-E University)

In the remaining two cases, there were no regular prior exchanges between the collaborating universities and companies. In one case, the collaboration resulted from an introduction by a different company that cooperated with the university. In the other case, the collaboration was initiated after the partner representatives met at an academic conference.

"There was no pre-existing relationship. Another company introduced us to this project. We needed technology and the university was looking for opportunities to use their technology. So, we were able to work together as our mutual goals were met." (UIR-D Company)

"I had not known the CEO of the company before. I met him at an academic conference. His company was wellknown in this field." (UIR-C University)

Interaction channels and intensity. All UIR collaborations were based on clear a priori agreements on how the work is divided among company and university partners. As a result, everyday interaction between the partners was mostly limited to emails and telephone conversations. Face-to-face interaction typically took place only on occasions when collaborative on-site work or major clarifications were necessary.

"We were in charge of electronic circuits and the university was focused on the machinery. Due to this division of work, most communication was short and was sent by email or phone. However, when we were conducting comprehensive experiments, we met the university partner face-to-face. " (UIR-A Company)

"We made occasional phone calls, on average, twice a month. Additionally, emails were exchanged from time to 
time when there was a need for communication. I met our partners in person about once per quarter to check the progress of the work." (UIR-C Company)

The UIR teams thought that informal social gatherings (e.g., dinner meetings) for establishing social relationships enhance communication quality. In three collaboration cases, social gatherings occurred with varying frequency after official meetings.

"During face-to-face meetings, we had lunch together, but did not have dinner or karaoke. The professor already knew our company well, but the university researchers did not. If you do not know each other well, social exchange is important. We were once treated for a good dinner by the university." (UIR-A Company)

"After each meeting, we had dinner and occasional drinks. Since we did not know each other well, we tried to have such gatherings for friendship. I think that such a way of forming a relationship is important." (UIR-D University)

For two cases, the UIR project teams did not have social gatherings. In one case, the partnership was with a women's university, and the company and university researchers did not socialize informally. They did not feel comfortable to have social gatherings between male company staff members and female university researchers. In the other case, the university professor was not interested in an informal social exchange with company staff.

Collaboration challenges and remedies. In most UIR cases, there were few open disagreements between the partners. In one UIR collaboration, different status and motivation was raising the possibility of a conflict. This was resolved by changing the company's project manager to a person who is more influential and more interested in the UIR collaboration.

"The company was manufacturing-oriented and their research center was not well equipped. This was disappointing to me. The director of the research center did not have leverage over the production manager. I participated in the production process and tried to look into the details more specifically, but it was not easy either, as the production people regarded our presence and frequent questions as a nuisance. So, I persuaded the CEO to appoint a more influential project manager, his son, to obtain better access to the production line." (UIRD University)

In another project, a Korean university and a US university were involved. The core technology was provided by the US university and the Korean university was responsible for transferring technology to the Korean company partner. In this project, securing the contract agreement with the US university partner constituted a major challenge.

"It took six months to finally sign the contract. The most difficult part of the settlement was about sales. A technology start-up company owned by the US university had shown a very sensitive response to the technology transfer. The company claimed royalties for potential product launches. So, the basic technology was transferred, but the specific technology related to the product was not. Furthermore, we agreed that the technology cannot be leveraged for sales when concluding the contract." (UIR-C University)

Collaboration outcomes. Three UIR collaborations ended with satisfying results for the participating companies and universities, which motivated them to conduct further research collaborations with the same partners. The collaboration outcomes included new technologies and new sales for the participating companies. The universities secured budgets for training student researchers and placed them in collaborating companies, in addition to knowledge acquisition, patents, and technology transfer.

"Securing research funding was a major achievement. We were able to train students and develop their skills and abilities." (UIR-A University)

"We look forward to improving speed, productivity and efficiency as initially expected. Overall, we are currently $80 \%$ satisfied. If we can turn the newly developed product into mass production, we will be 100\% satisfied." (UIR-D Company)

"At the beginning, we did not have much expectation that this UIR project could contribute to our sales. However, we have already achieved sales of about 150 million USD as a result of this collaboration." (UIR-E Company)

On the other hand, the outcomes of two UIR collaborations were regarded as unsatisfactory by the participating companies and universities. The collaboration partners felt that they could not meet the set project targets or achieve other tangible outcomes.

"We aimed to develop products and contribute to the company's overseas sales. However, it was much harder than I thought, and I cannot be satisfied. The product performance was lower than expected. I think there is a mountain that has to be overcome for effective commercialization." (UIR-B University)

"The market situation needs to be observed further. The project is overall not so satisfying for us, as our competitors released the same product. Additionally, the organization of UIR collaborations can be improved." (UIR-C Company) 


\section{Discussion and Propositions}

The in-depth analysis of ten research collaborations in Korea has yielded various findings that help deepen the understanding of the role of pre-existing social ties and relational orientation in such collaborations.

Related to our first research question, we found preexisting social ties between collaboration partners in most collaboration cases, supporting the notion that they are prevalent in business exchanges in Korea (Horak, 2014; 2017) and indicating their abundance not only in transforming economies such as China (Luo et al., 2012), but also in East Asian NIEs. However, we found a high variation in the type and quality of the pre-existing social ties. For two out of three NPD collaborations with preexisting ties, these ties can be described as long-term interorganizational ties between the partnering companies with weak personal-level ties. The personal-level ties are the result of the inter-organizational ties, but not vice versa. In only one NPD collaboration case, strong pre-existing social ties are reported. One member of the collaboration team previously worked for the partner company. While tie strength is generally understood as a multinational construct which reflects the closeness and intensity of a relationship (Granovetter, 1973), perceived tie strength is primarily based on the strength of emotional bonds between partners in the Korean context (Yang, 2006).

Similarly, among three UIR cases with pre-existing ties, these ties were relatively weak and spurious in one case when the company previously supplied the university with research materials. Only in the remaining two UIR cases, the pre-existing ties can be classified as strong. The university professor was a co-founder of the company or previously worked for the company as director of the research department.

Furthermore, the pre-existing social ties identified in both types of research collaborations do not fall into the categories of yongo ties that are frequently emphasized in Korea (family, school/university, or regional). This finding is remarkable, as these categories of ties are believed to be highly relevant in contemporary business exchanges in Korea (Lew, Chang, \& Kim, 2013; Horak, 2014). Our analysis does not support this notion in the context of research collaborations. We found both strong and weak ties, and even the strong ties were developed from a previous professional (not private) relationship. Therefore, we propose:

Proposition 1: Pre-existing social ties are prevalent in research collaborations in Korea, but strongly vary in strength and tend to be rooted in previous professional exchanges, not personal relationships such as family, school/university or regional ties.

Addressing our second research questions, our analysis suggests that regardless of the type of pre-existing social ties, such ties are effective for initiating research collaborations in Korea, but not necessarily for enhancing positive outcomes.

We found that pre-existing social ties played a role in initiating three NPD collaborations and three UIR collaborations. However, we also found cases where the partners relied on different mechanisms for initiating research collaborations, such as third party introduction or partner reputation. These findings are in line with trust research which has identified pre-existing social ties, third party introduction and partner reputation for collaboration initiation as trust-building mechanisms in business exchanges which can be associated with prediction-based, transference-based and capability-based trust-building, respectively (Doney, Cannon, \& Mullen, 1998, Yang \& Cho, 2015). Our findings suggest that pre-existing ties are a frequent mechanism for initiating research collaborations in Korea. However, they are by no means indispensable for the setup of such collaborations, but can be complemented or substituted by other mechanisms. Therefore, we propose:

Proposition 2: Pre-existing social ties, partner reputation and third-party introduction are effective mechanisms to initiate research collaborations in Korea.

While we found pre-existing social ties to be effective for initiating research collaborations in Korea, we did not find them to be positively related to collaboration outcomes. On the contrary, some non-successful collaborations were based on strong pre-existing social ties. Among the NPD collaborations, the only case in which strong pre-existing social ties were identified is the only one that was perceived as a failure. Similarly, in one UIR case, the university professor was previously the company's director of research. This UIR collaboration resulted in non-satisfactory outcomes. Conversely, two NPD collaborations and one UIR collaboration resulted in positive outcomes in the absence of pre-existing social ties.

These findings do not necessarily imply that pre-existing social ties are generally detrimental for achieving positive outcomes in research collaborations in Korea. However, social ties appear to be only helpful when they result in collaborations with competent and motivated partners that solve technical and managerial problems during the collaboration, avoiding lock-in effects with ineffective partners (Ledeneva, 2018). For example, two successful NPD collaborations were supported by strong interorganizational ties, and weak inter-personal ties. In these collaborations, the partners focused on solving task-related problems and did not establish strong inter-personal social ties, which were not needed for achieving positive outcomes Conversely, in one NPD collaboration, strong pre-existing social ties did not result in positive outcomes. The ties did not prevent one company to behave in a way to be perceived as opportunistic by the partner. Therefore, we propose:

Proposition 3: Pre-existing social ties enhance outcomes of research collaborations in Korea only when they result 
in collaborations with competent and motivated partners.

Related to our third research question, we observed a strong relational orientation in most research collaborations. This relational orientation is not limited to projects with preexisting social ties between the partners. In NPD collaborations and UIR collaborations, most collaboration partners engaged in frequent interaction to establish a close relationship and to achieve positive outcomes. Clearly, relational governance is regarded as more relevant than contractual agreements in research collaborations in Korea, confirming the findings of a quantitative study on NPD collaborations (Bstieler \& Hemmert, 2015).

Across both types of research collaborations, relational orientation articulates itself not only through task-related interaction between collaboration partners, which studies on relational governance in NPD collaborations have mostly focused on (e.g., Heide \& John, 1992; Bstieler \& Hemmert, 2015), but also through separate social gatherings such as lunch or dinner meetings, and shared leisure activities such as karaoke singing, sauna visits, or golfing. For NPD collaborations and UIR collaborations, various participants emphasized the importance of such social events for smoothly running the collaboration. In Korea, individuals frequently engage in social exchanges for creating 'jeong' (empathy or emotion) with others to establish an emotional basis in their relationship with counterparts, which is deemed important for effective collaboration (Yang, 2006; Yang \& Horak, 2019). Therefore, we propose:

\section{Proposition 4: Relational orientation in research collaborations in Korea is strong and frequently articulates itself in task-related and social exchanges.}

Finally, and addressing our fourth research question, we found that the relational orientation of NPD collaboration and UIR partners in Korea tends to enhance collaboration outcomes. Various collaboration managers expressed their views that relational orientation and investments into relationship building are important for enhancing positive outcomes of research collaborations. These findings are in line with extant NPD collaboration research which suggests that strong relationships between partners help to address the challenges that frequently evolve in NPD collaborations, such as tensions over contributions and benefits, potential competitive conflicts, or concerns about potential misappropriation of technological knowledge (Bstieler, 2006). In a UIR context, open disagreements are less prevalent but the partners often struggle to bridge their different mindsets and procedures (Bruneel, D'Este, \& Salter, 2010; Hemmert, Bstieler, \& Okamuro, 2014). Our findings indicate that relational orientation appears to be instrumental for addressing these challenges, enhancing partners' mutual understanding, and achieving positive outcomes. Building emotional bonds with collaboration partners is generally seen as important in Korea for establishing productive relationships (Yang, 2006; Yang \&
Horak, 2019).

Regardless of the observed positive link between relational orientation and outcomes, we found that frequent task-related and social interaction during a collaboration is not always sufficient for achieving positive results, however. To illustrate, frequent task-related communication, face-toface meetings and social gatherings could not prevent the breakdown of the collaboration in one NPD collaboration case due to the perceived non-cooperative behavior of the partner. Therefore, we propose:

Proposition 5: Relational orientation in research collaborations in Korea is a positive antecedent, but not a sufficient condition for outcomes.

\section{Conclusions}

\subsection{Theoretical Implications}

This study contributes to the understanding of the role of informal networks in Korean business exchanges in various ways. First, we found that while pre-existing social ties are prevalent in research collaborations, they do not fall into any of the categories of yongo ties, which have been studied extensively in the literature on informal social ties in Korea (e.g., Yee, 2000, Lew, 2013; Horak, 2014; Yang \& Horak, 2019). Instead, pre-existing social ties are mostly based on previous professional interaction. This suggests that such "non-traditional" ties should be given more attention in subsequent research on social ties in Korean business exchanges.

Second, we found that relational orientation in research collaborations in Korea is very widespread and frequently expresses itself in informal social exchanges such as shared meals or leisure activities. Western business collaboration research has mostly focused on task-related processes when studying relational governance (Heide \& John, 1992; Dyer \& Singh, 1998). Our findings indicate that in a non-Western context, informal social exchange is a major and important part of relational orientation in research collaborations. Therefore, informal exchange mechanisms, such as 'jeong' in Korea, should be given more attention in future business collaboration research.

Third, we found different roles of the two major aspects of informal networks: pre-existing social ties prior to a collaboration and relational orientation during a collaboration. Pre-existing social ties appear to be a doubleedged sword in the context of research collaborations in Korea. They are a helpful mechanism for collaboration initiation, but lead to positive outcomes only when they are well-aligned with professional requirements, resulting in the selection of competent and motivated partners and a clear mutual understanding on the roles and responsibilities of each partner. Otherwise, their bright side in helping to establish collaborations may yield to a dark side of 
collaboration breakdown due to mutual disappointment and ensuing negative emotions, particularly when the collaboration partner has been selected based on pre-existing social ties, and not professional competencies. Conversely, relational orientation clearly has a bright side in strengthening the mutual understanding of collaboration partners and facilitating positive outcomes, with no discernible dark side, at least in the context of the focal research collaboration. These results indicate that the role of informal networks should be studied in a more fine-grained manner for research on business exchanges by differentiating between specific aspects such as pre-existing social ties and relational orientation, and the bright or dark side of these aspects.

Finally, our study showed a high prevalence and importance of informal networks in research collaborations in Korea, which include pre-existing social ties and a strong relational orientation throughout collaboration projects. Our findings indicate that informal networks maintain their importance not only in transforming economies such as China, but also in East Asian NIEs such as Korea. The results suggest that at least in East Asia, relational exchange is not necessarily rendered obsolete by institutional transitions and economic development, as suggested by Peng (2003). The continued relevance of informal networks in Korea appears to be rooted in Confucian cultural traditions. Such cultural background factors may need more attention when theorizing about institutional development and transition.

\subsection{Managerial Implications}

Pre-existing social ties are an effective mechanism to initiate research collaborations in Korea. However, they can be detrimental for outcomes when they do not result in the selection of competent and motivated partners and a clear mutual understanding of their roles and responsibilities. Therefore, it is important for collaboration managers in Korea to rely only on pre-existing social ties that are wellaligned with task-related requirements when initiating and conducting research collaborations.

Our study suggests that the intensity of task-related and social interaction between collaboration partners often enhances collaboration outcomes. The partners feel more at ease when exchanging important information and working together intensively under a perceived close relationship. Such close relationships between collaboration partners neither strictly prevent trust transgressions by the partner nor guarantee positive outcomes. However, they often enhance collaboration outcomes in terms of learning, knowledge acquisition and eventually, business performance. Therefore, collaboration managers in Korea should encourage the creation of strong relationships between collaboration team members of partnering organizations, including social gatherings, which should be regarded as an investment into relationship building rather than an irrelevant leisure activity or a waste of time.

\subsection{Limitations and Further Research Directions}

This study has some limitations, which may be addressed in future research. We study only a small sample of ten research collaborations in a quest to improve the understanding of the role of pre-existing social ties and relational orientation in such collaborations, and the mechanisms through which they influence collaboration outcomes. However, due to our small sample, the findings cannot be easily generalized. Future studies may convert our propositions into hypotheses that can be tested for larger samples of research collaborations.

Our study covers only two specific types of research collaborations (NPD collaborations and UIR collaborations) in Korea. Future studies may verify our findings for different types of collaborations and business exchanges and in different countries or regions.

\section{References}

Bruneel, J., D'Este, P., \& Salter, A. (2010). Investigating the factors that diminish the barriers to university-industry collaboration. Research Policy, 39(7), 858-868.

Bstieler, L. (2006). Trust formation in collaborative new product development. Journal of Product Innovation Management, 23(1), 56-72.

Bstieler, L., \& Hemmert, M. (2010). Trust formation in Korean new product alliances: How important are preexisting social ties? Asia Pacific Journal of Management, 27(3), 299-319.

Bstieler, L., \& Hemmert, M. (2015). The effectiveness of relational and contractual governance in new product development collaborations: Evidence from Korea. Technovation, 45-46, 29-39.

Bu, N., \& Roy, J.-P. (2015). Guanxi practice and quality: A comparative analysis of Chinese managers' business-tobusiness and business-to-government ties. Management and Organization Review, 11(2), 263-287.

Burt, R. S., \& Burzynska, K. (2017). Chinese entrepreneurs, social networks, and Guanxi. Management and Organization Review, 13(2), 221-260.

Chen, X.-P., \& Chen, C. C. (2004). On the intricacies of the Chinese Guanxi: A process model of Guanxi development. Asia Pacific Journal of Management, 21(3), 305-324.

Doney, P. M., Cannon, J. P., \& Mullen, M. R. (1998). Understanding the influence of national culture on the development of trust. Academy of Management Review, 23(3), 601-620.

Dyer, J. H., \& Singh, H., (1998). The relational view: Cooperative strategy and sources of interorganizational competitive advantage. Academy of Management Review, 22(4), 660-679.

Eom, B.-Y., \& Lee, K. (2010). Determinants of industry- 
academy linkages and their impact on firm performance: The case of Korea as a latecomer in knowledge industrialization. Research Policy, 39(5), 625-639.

Goo, J., Kishore, R., Rao, H. R., \& Nam, K. (2009). The role of service level agreements in relational management of information technology outsourcing: An empirical study. MIS Quarterly, 33(1), 119-145.

Granovetter, M. (1973). The strength of weak ties. American Journal of Sociology, 78(6), 1360-1380.

Heide, J. B., \& John, G. (1992). Do norms matter in marketing relationships? Journal of Marketing, 56(2), $32-44$.

Hemmert, M., Bstieler, L., \& Okamuro, H. (2014). Bridging the cultural divide: Trust formation in university-industry research collaborations in the US, Japan, and South Korea. Technovation, 34(10), 605-616.

Hemmert, M. (2018). The evolution of tiger management: Korean companies in global competition. Oxon and New York: Routledge.

Hemmert, M. (2019). The relevance of inter-personal ties and inter-organizational tie strength for outcomes of research collaborations in South Korea. Asia Pacific Journal of Management, 36(2), 373-393.

Horak, S. (2014). Antecedents and characteristics of informal relation-based networks in Korea: Yongo, yonjul and inmaek. Asia Pacific Business Review, 20(1), $78-108$.

Horak, S. (2017). The informal dimension of human resource management in Korea: Yongo, recruiting practices and career progression. International Journal of Human Resource Management, 28(10), 1409-1432.

Horak, S., \& Taube, M. (2016). Same but different? Similarities and fundamental differences of informal social networks in China (guanxi) and Korea (yongo). Asia Pacific Journal of Management, 33(3), 595-616.

Huff, L., \& Kelley, L. (2003). Levels of organizational trust in individualist versus collectivist societies: A sevennation study. Organization Science, 14(1), 81-90.

Kwon, O. Y. (2010). The Korean economy in transition: An institutional perspective. Cheltenham: Edward Elgar.

Ledeneva, A. (2018). Introduction: The informal view of the world - key challenges and main findings of the global informality project. In A. Ledeneva (Ed.), The Global Encyclopedia of Informality: Understanding Social and Cultural Complexity, Vol. 1: 1-27. London: UCL Press.

Lee, K., \& Lim, C. (2001). Technological regimes, catchingup and leapfrogging: Findings from the Korean industries. Research Policy, 30(3), 459-483.

Lee, S., Park, G., Yoon, B., \& Park, J. (2010). Open innovation in SMEs: An intermediated network model.
Research Policy, 39(2), 290-300.

Lew, S.-C. (2013). The Korean economic developmental path: Confucian tradition, affective network. New York: Palgrave Macmillan.

Lew, S.-C., Chang, M.-H., \& Kim, T.-E. (2013). Affective networks, social capital, and modernity in Korea. In S.-C. Lew (Ed.), The Korean economic developmental path: Confucian tradition, affective network (pp.49-73). New York: Palgrave Macmillan.

Luo, Y., Huang, Y., \& Wang, S. L. (2012). Guanxi and organizational performance: A meta-analysis. Management and Organization Review, 8(1), 139-172.

OECD - Organization for economic co-operation and development (2017). OECD Science, Technology and Industry Scoreboard 2017: The Digital Transformation. Paris: OECD Publishing.

Park, J. H., \& Shim, H. (2019). R\&D Intensity and regulation fair disclosure. Journal of Asian Finance, Economics and Business, 6(1), 281-288.

Peng, M. W. (2003). Institutional transitions and strategic choices. Academy of Management Review, 28(2), 275296.

van de Vrande, V., de Jong, J. P. J., Vanhaverbeke, W., \& de Rochemont, M. (2009). Open innovation in SMEs: trends, motives and management challenges. Technovation, 29(6-7), 423-437.

West, J., \& Bogers, M. (2014). Leveraging external sources of innovation: A review of research on open innovation. Journal of Product Innovation Management, 31(4), 814831.

Yang, I. (2006). Jeong exchange and collective leadership in Korean organizations. Asia Pacific Journal of Management, 23(3), 283-298.

Yang, I., \& Horak, S. (2019). Emotions, indigenous affective ties, and social network theory: The case of South Korea. Asia Pacific Journal of Management, 36(2), 395-414.

Yang, H. C., \& Cho, H. Y. (2015). Small and medium business workers' positive psychological capital, life satisfaction, and innovative work behavior. Journal of Distribution Science, 13(7), 25-31.

Yee, J. (2000). The social networks of Koreans. Korea Journal, 40(1), 325-352.

Yee, J. (2015). Social capital in Korea: Relational capital, trust, and transparency. International Journal of Japanese Sociology, 24, 30-47.

Yum, J. O. (1988). The Impact of Confucianism on interpersonal relationships and communication patterns in East Asia. Communication Monographs, 55(4), 374388. 